\title{
SEISMIC BEHAVIOR OF RCC DAMS INCLUDING THE EFFECT OF FOUNDATION
}

\author{
Z. Heirany ${ }^{\mathrm{a}, *}$ \\ a * Department of Civil Engineering, Parand Branch, Islamic Azad University, Parand, Iran \\ e-mail: zheirany@gmail.com
}

Received: 14.09.2017 / Accepted: 20.09.2017 / Revised: 16.11.2017 / Available online: 15.12.2017

DOI: 10.1515/jaes-2017-0011

KEY WORDS: Roller Compacted Concrete (RCC), dam - foundation interaction, boundary conditions, nonlinear dynamic analysis

\begin{abstract}
:
Roller Compacted Concrete (RCC) dams are actually a combination of concrete dams' safety and procedure of earth dam while accelerating construction and reducing administrative costs, have high safety. And why in the world and Iran, constructing this type of dam has growing trend. The first roller compacted concrete (RCC) dam of Iran (Jegin dam) has come into operation in 2006. In terms of expressed statistics and given that, none of these dams has not been subject to severe earthquake, roller concrete dam operations is not specified in facing with severe earthquake and its merits and faults. Therefore, the need for seismic analysis of these dams in the design, implementation and operation is obvious. In the meantime, the lack of studies on how modeling of roller compacted concrete (RCC) dams using finite element software, especially on how to foundation modeling (dimensions, material properties, interaction of foundation and dam), modeling dam lake (the length of lake, the water level, the interaction between the lake and the dam body) felt. In this study, dynamic analysis of roller compacted concrete (RCC) dam using ABAQUS finite element software and modeling one of the roller compacted concrete (RCC) dams of Malaysia with the change approach of foundation boundary conditions will be considered.
\end{abstract}

\section{INTRODUCTION}

Reservoir dams are multi-national mega-projects which the water supply for drinking, agriculture, industry, power generation, floods control, tourism, cultural and recreational affairs are their purposes which are considered as the critical projects of each country. Roller compacted concrete dam (RCC) is one of the types of concrete gravity dams that in its design, all the terms and design considerations of a typical concrete gravity dam must be respected. This method is used in implementation of concrete pavement road and roller compacted concrete (RCC) dams. The use of RCC in construction of concrete dams has significant economic benefits and speed of operation compared to conventional concrete dams and is considered as successful experiences and efforts of dam in the last decade (Zhou et al 2005, WU et al 2001).

The first RCC dam built in the USA was Willow Creek Dam in Oregon on a tributary of Columbia River. US Army Corps of Engineers initiated such construction between November 1981 and February 1983. In our country Iran because of anonymity, use option of roller concrete dams was considered to dam construction industry practitioners with delay. Karkhe regulating dam with a height of 34 meters was carried out using RCC method. Jegin RCC dam with a height of $78 \mathrm{~m}$ from foundations, Zirdan dam with a height of $63 \mathrm{~m}$, Rudbar Lorestan dam and Shafaroud Gilan dam was carried out using RCC method.
Many researchers have focused on studying the various aspects of the new technology, including Chuhan, Guanglun and Shaomin in 2002, presented the results of laboratory tests on samples of RCC and non-linear failure analysis of RCC dams. In this study, samples of RCC used were prepared in Longtan dam construction in China. By doing experiments on them, nonlinear parameters required and tension - strain curve in tension for use in nonlinear analysis was obtained. Using a numerical program entitled NFAGD with nonlinear failure criterion and rupture pressure - cutting largest block Longtan dam to a height of 200 meters was placed under the non-linear seismic analysis. Stone foundation of dam, without mass and with a depth equal to the height of the dam was meshed. To consider the interaction between the dam and the lake, the added mass method was used. Zhang and Peng in 2004, threedimensional finite element model of a block of Longtan dam that it is a step in the wake of the toe prepared and placed under the dynamic analysis. In this study, the interaction of the dam, stone foundation and container, have been considered.

Zuohui in 2004, presented a numerical model to simulate the concrete behavior of RCCD dams where the relationship of tension - strain with multi-layered structure to describe the elastic and elasto-plastic behavior is modeled. As a practical example, finite element model of Longtan dam with four different mixes of RCC with different strength properties in different parts of the body were analyzed. It should be noted 
that in connection with the dam foundation of massive concrete has been used.

Esmaeilnia Omran and Mehdilu Torkamani (2012), in a study paid to review the safety and stability control of Jegin RCC dam using dynamic time history analysis. The results show that Jegin dam is in good condition in terms of stability and safety and this dam is stable and safe against static and dynamic loads. Julie et al (2013), in a study paid to resistance dynamic analysis of roller concrete dam in Prince Edward Island against earthquakes using finite element analysis and monitoring methods. The results showed that the numerical method used in this paper could well simulate the seismic response of dams and in future plans are useful in assessing the safety of RCC dams.

\section{DAM-FOUNDATION INTERACTION}

The effect of soil-structure interaction is usually important when the structure is a kind of bulky and heavy structures or that cannot be neglected structural rigidity against the rigidity of soil or rock foundation. Under these conditions, stimulate the inflow to the dam cannot be considered only from the elementary excitations of the earth and this motivation will be influenced by the interaction of soil and dam. A dam is located on the ground when faced with a dynamic loading, for example, seismic load, have interaction with the surrounding soil. Unlike dam, foundation soil is an unlimited environment with geometric damping and this situation should be considered in dynamic modeling. For modeling of wave propagation in the soil, two foundation methods without mass and massed foundation method are used. For this purpose the boundary conditions must be defined in such a way that borders are wave energy absorber rebound from structures to the extreme environment, known as damping radiation. To model the soil, soil dynamic stiffness matrix must be calculated. It means that the dynamic stiffness matrix is the relationship between the force and spatial variations in soil surface with the structures. For example, in the frequency domain if the load is as $R(\omega)=R_{0}(\omega) e^{i \omega t}$, spatial variations will be as $u(\omega)=u_{0}(\omega) e^{i \omega t}$ and as a result, the dynamic stiffness matrix will be equal to:

$$
\begin{aligned}
& {[M][\ddot{u}]+[C][\dot{u}]+[K][u]=R} \\
& \left(-\omega^{2}[M]+i \omega[C]+[K]\right)\left(u_{0}(\omega)\right]=\left[R_{0}(\omega)\right] \\
& S(\omega)\left[u_{0}(\omega)\right]=\left[R_{0}(\omega)\right]
\end{aligned}
$$

In the above equation, $S(\omega)$ known as the dynamic stiffness matrix or impedance function. At the time space also the dynamic stiffness matrix to be calculated using a combination of the following series of integrals (Wolf 1985, Ghaemian, 2000).

$$
\{R(t)\}=\int_{0}^{t}\left[S^{\infty}(1-\tau)\right]\{u(\tau)\} d \tau
$$

The dynamic stiffness matrix of structure also set up the same way:

$$
\left\{[ \begin{array} { l l } 
{ [ S _ { s s } ] } & { [ S _ { s b } ] } \\
{ [ S _ { b s } ] } & { [ S _ { b b } ^ { s } }
\end{array} ] \left\{\left\{\begin{array}{l}
{\left[u_{s}^{t}\right]} \\
{\left[u_{b}^{t}\right]}
\end{array}\right\}=\left\{\begin{array}{l}
{\left[R_{s}\right]} \\
{\left[R_{b}^{s}\right]}
\end{array}\right\}\right.\right.
$$

In the above equation $S$ index is for structural degrees of freedom and $b$ index is for the degree of freedom of contact location of structure and soil. [Rs] are forces that effect on structural nodes. $\left[R_{b}^{s}\right]$ are forces that effect on the confluence nodes of structure and soil. If $\left[R_{b}^{g}\right]$ are contact local forces of soil and structure originates from soil substructure given the balance of forces at the contact location of soil and structure, equation (6) is established between the forces.

$$
\left[R_{b}^{g}\right]=-\left[R_{b}^{s}\right]
$$

If the displacement in the location of soil and structure in the absence of structure ${ }^{\left[u_{b}^{g}\right]}$, in the presence of structure $\left[u_{b}^{t}\right]$ and impedance function matrix ${ }^{\left[S_{b b}^{g}\right]}$, the amount of force generated at the contact location of soil and structure in the presence of structures will be equal to:

$$
\left[R_{b}^{s}\right]=-\left[R_{b}^{g}\right]=-\left[S_{b b}^{g}\right]\left(\left[u_{b}^{t}\right]-\left[u_{b}^{g}\right]\right)
$$

By substituting equation (7) in equation (5), equation (8) is obtained:

$$
\left\{\begin{array}{ll}
{\left[S_{s s}\right]} & {\left[S_{s b}\right]} \\
{\left[S_{b s}\right]} & {\left[S_{b b}^{s}\right]}
\end{array}\right]\left\{\left\{\begin{array}{l}
{\left[u_{s}^{t}\right]} \\
{\left[u_{b}^{t}\right]}
\end{array}\right\}=\left\{\begin{array}{c}
{\left[R_{s}\right]} \\
{\left[S_{b b}^{g}\right]\left(\left[u_{b}^{g}\right]-\left[u_{b}^{\prime}\right]\right)}
\end{array}\right\}\right.
$$

Then:

$$
\left\{\begin{array}{lr}
{\left[S_{s s}\right]} & {\left[S_{s b}\right]} \\
{\left[S_{b s}\right]} & {\left[S_{b b}^{s}\right]+\left[S_{b b}^{g}\right]}
\end{array}\right\}\left\{\begin{array}{l}
{\left[u_{s}^{t}\right]} \\
{\left[u_{b}^{t}\right]}
\end{array}\right\}=\left\{\begin{array}{c}
{\left[R_{s}\right]} \\
{\left[S_{b b}^{g}\right]\left[u_{b}^{g}\right]}
\end{array}\right\}
$$

In this study, nonlinear dynamic analysis of Kinta dam in order to case studies to assess the impact of changes in terms of foundation including changes in the elastic modulus, changes in foundations boundary conditions in different horizontal and vertical earthquake accelerations on the tension of the roller compacted concrete (RCC) dams using Abaqus program will be discussed. Kinta dam is the first roller compact concrete built in Malaysia at a distance of approximately 200 kilometers north of Kuala Lumpur. Construction of this dam began in the third September 2004 on Quinta River.

Loading of Kinta dam in the analysis included weight load, hydrostatic pressure and loads originates from earthquake. The effect of uplift pressure in the dynamic analysis of dam is not considered. The sediment load is neglected due to its low height. For loading the weight of dam and foundation bodies, 2325 and $2650 \mathrm{~kg}$ per cubic meter values are used as the density of each, respectively. In this loading, the weight of accessories such as valves is ignored. In order to consider the hydrostatic pressure, water level of the dam in full reservoir is considered equal to $76.8 \mathrm{~m}$. For earthquake loading of Kinta dam, horizontal and vertical components of Tabas earthquake are used. In this study, vertical and horizontal components of the earthquake in terms of DBE and MCE are shown in Table 1.

Table1. Horizontal and vertical components of the earthquake in terms of $\mathrm{DBE}$ and $\mathrm{MCE}$

\begin{tabular}{|c|c|c|}
\hline Tabas earthquake & DBE & MCE \\
\hline Horizontal component & $0.26 \mathrm{~g}$ & $0.692 \mathrm{~g}$ \\
\hline Vertical component & $0.098 \mathrm{~g}$ & $0.295 \mathrm{~g}$ \\
\hline
\end{tabular}




\section{FOUNDATION BOUNDARY CONDITIONS}

In this study, two boundary conditions for the foundation are considered. In the first boundary condition in all respects, the foundation is assumed to be fixed.

Second condition holds steady only the nodes under the foundation and in the rest of the peripheral nodes of foundation, models the damper.

In this study, 20 different samples to assess the effect of foundation on seismic performance of roller compacted concrete (RCC) dams with a density of 2325 kilograms per cubic meter and modulus of elasticity of $22.5 \mathrm{Gpa}$ and Poisson's ratio of 0.2 to dam materials and the density of 1000 kilograms per cubic meter and wave speed of $1440 \mathrm{~m}$ per second for the water reservoir and Poisson's ratio of 0.3 for the foundation built that their specifications based on the change in boundary conditions of foundation and the modulus of elasticity of foundation and horizontal and vertical earthquake represented in Table 2.

Table 2. Specifications of different samples

\begin{tabular}{|c|c|c|c|c|}
\hline $\begin{array}{c}\text { Sample } \\
\text { Number }\end{array}$ & $\begin{array}{l}\text { Earthquake } \\
\text { components }\end{array}$ & $\begin{array}{l}\text { Foundations } \\
\text { boundary } \\
\text { condition }\end{array}$ & $\begin{array}{c}\text { Foundations } \\
\text { density - kg } \\
\text { per cubic } \\
\text { meter }\end{array}$ & $\begin{array}{c}\text { Foundation } \\
\text { modulus of } \\
\text { elasticity - } \\
\quad \mathrm{GPa}\end{array}$ \\
\hline 1 & $\begin{array}{l}\text { Horizontal - } \\
\text { DBE }\end{array}$ & First & Without mass & 15 \\
\hline 2 & $\begin{array}{c}\text { Horizontal - } \\
\text { DBE }\end{array}$ & Second & Without mas5 & 15 \\
\hline 3 & $\begin{array}{l}\text { Horizontal - } \\
\text { MCE }\end{array}$ & First & 2650 & 5 \\
\hline 4 & $\begin{array}{l}\text { Horizontal - } \\
\text { MCE }\end{array}$ & First & 2650 & 15 \\
\hline 5 & $\begin{array}{l}\text { Horizontal - } \\
\text { MCE }\end{array}$ & Firgt & 2650 & 22.5 \\
\hline 6 & Vice - MCE & First & 2650 & 5 \\
\hline 7 & Vice - MCE & Firgt & 2650 & 15 \\
\hline 8 & Vice - MCE & First & 2650 & 22.5 \\
\hline 9 & Vice - MCE & First & Without mass & 15 \\
\hline 10 & $\begin{array}{l}\text { Horizontal - } \\
\text { MCE }\end{array}$ & Firgt & Without mas5 & 15 \\
\hline 11 & $\begin{array}{l}\text { Horizontal - } \\
\text { MCE }\end{array}$ & Second & 2650 & 5 \\
\hline 12 & $\begin{array}{l}\text { Horizontal - } \\
\text { MCE }\end{array}$ & Second & 2650 & 15 \\
\hline 13 & $\begin{array}{l}\text { Horizontal - } \\
\text { MCE }\end{array}$ & Second & 2650 & 22.5 \\
\hline 14 & Vice - MCE & Second & 2650 & 5 \\
\hline 15 & Vice - MCE & Second & 2650 & 15 \\
\hline 16 & Vice - MCE & Second & 2650 & 22.5 \\
\hline 17 & $\begin{array}{l}\text { Horizontal - } \\
\text { MCE }\end{array}$ & Second & Without mass & 15 \\
\hline 18 & Vice - MCE & Second & Without mass & 15 \\
\hline 19 & Vice - DBE & First & Without mass & 15 \\
\hline 20 & Vice - DBE & Second & Without mass & 15 \\
\hline
\end{tabular}

Using the analysis model by software, the results of the evaluation of different situations on the tension of the dam foundation and deformations resulting in dam body was found as Figures 3 and 4 and Table 5.
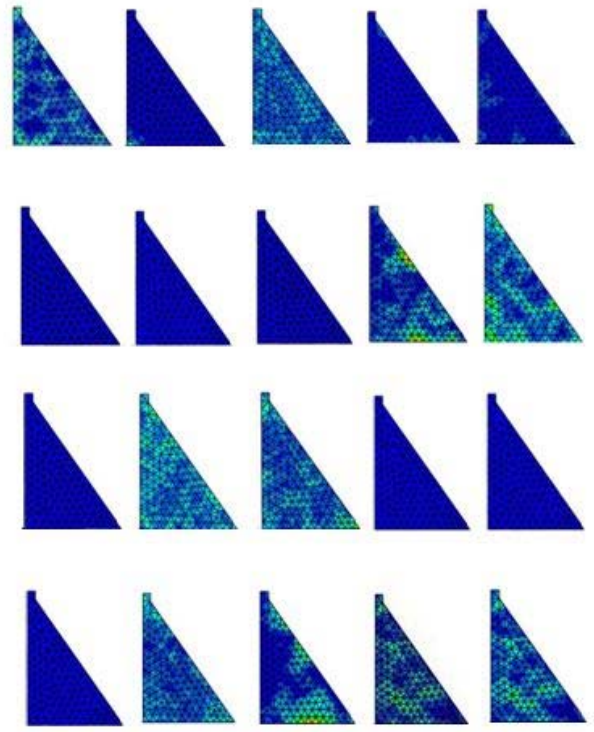

Figure 3. Maximum principal tensions in models 1 to 20
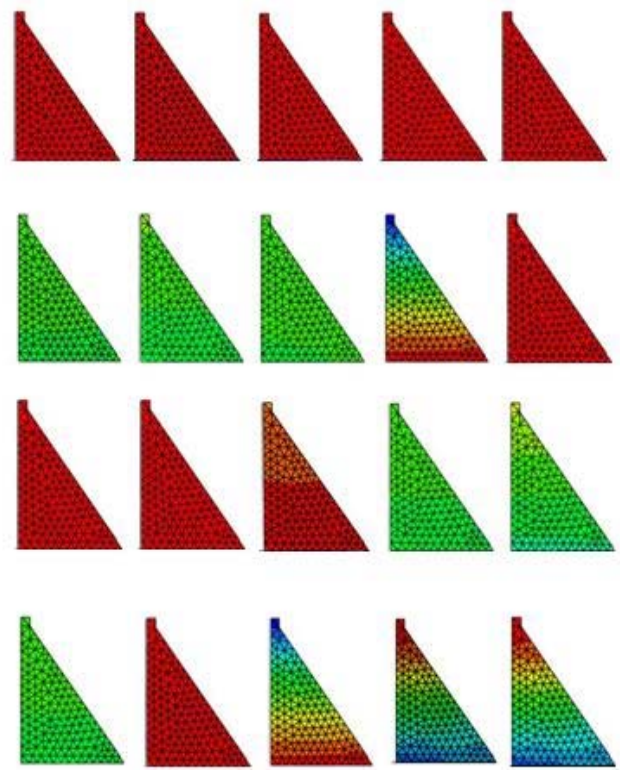

Figure 4. Maximum deformation in models 1 to 20 
Table 5. Tensions values and displacement in models 1 to

\begin{tabular}{|c|c|c|c|c|}
\hline $\begin{array}{l}\text { Sample } \\
\text { Number }\end{array}$ & $\begin{array}{c}\text { The } \\
\text { maximum } \\
\text { principal } \\
\text { tension - } \\
\mathrm{MPa} \\
\end{array}$ & $\begin{array}{l}\text { The } \\
\text { minimum } \\
\text { principal } \\
\text { tension - } \\
\mathrm{MPa} \\
\end{array}$ & $\begin{array}{c}\text { The } \\
\text { maximum } \\
\text { horizontal } \\
\text { displacement } \\
\text { - mm }\end{array}$ & $\begin{array}{c}\text { The } \\
\text { maximum } \\
\text { vertical } \\
\text { displacement } \\
\text { - mm } \\
\end{array}$ \\
\hline 1 & 0.01607 & 0.0003885 & 1281 & 0.06335 \\
\hline 2 & 0.09471 & 0.00983 & 1281 & 0.1294 \\
\hline 3 & 7.147 & 0.1469 & 3398 & 23.5 \\
\hline 4 & 0.6665 & 0.004267 & 3400 & 3.896 \\
\hline 5 & 1.65 & 0.001301 & 3398 & 3.101 \\
\hline 6 & 0.07088 & 0.001092 & 1.937 & 1449 \\
\hline 7 & 0.03616 & 0.0009597 & 0.4591 & 1449 \\
\hline 8 & 0.04719 & 0.0007839 & 0.3408 & 1449 \\
\hline 9 & 0.0003604 & 0.000007407 & 0.004123 & 1455 \\
\hline 10 & 0.009765 & 0.001696 & 3409 & 0.1817 \\
\hline 11 & 3.893 & 0.01204 & 3420 & 39.24 \\
\hline 12 & 5.893 & 0.02137 & 3396 & 31.17 \\
\hline 13 & 134.9 & 2.226 & 3618 & 650.7 \\
\hline 14 & 0.8962 & 0.001213 & 2.713 & 1449 \\
\hline 15 & 0.06473 & 0.00261 & 0.4176 & 1449 \\
\hline 16 & 0.08216 & 0.001139 & 0.4824 & 1449 \\
\hline 17 & 0.01625 & 0.0004012 & 3409 & 0.1747 \\
\hline 18 & 0.0004383 & 0.00001334 & 0.003414 & 1455 \\
\hline 19 & 0.0001145 & 0.000003035 & 0.00008109 & 482.4 \\
\hline 20 & 0.0001041 & 0.000003734 & 0.00007393 & 482.4 \\
\hline
\end{tabular}

\section{CONCLUSIONS}

Considering the mass, flexibility and resonance damping for the foundation, the of response roller compacted concrete dam seems more logical. Including damping in nonlinear dynamic analysis of massive foundations reduces displacement of dam crest which may decrease system failure. In the non-linear dynamic analysis reducing the ratio Ef / ES causes reduced displacement and therefore crack profiles. By comparing samples 1 and 4 and samples 2 and 12 is determined that the earthquake in MCE mode imposed more tensions and displacements than the DBE mode to the system. The comparison of samples 1 and 2 and samples 9 and 18 shown a second boundary condition in the case of massless foundation will have more tensions and displacements. The comparison of samples 3, 4, 5 and samples $6,7,8$ shown in mass foundation in the first boundary condition, by increasing the elastic modulus of the foundation, somewhat reduced tensions and displacements. By comparing samples 11, 12, 13 and samples $14,15,16$ shown that in the second boundary condition in the case of horizontal earthquake, tensions and displacements have increased and in the case of vertical earthquake have decreased. By comparing samples 4 and 10 and samples 7 and 9 shown in massless foundation in the first boundary condition, imposed less tensions to the system. Comparison of samples 12 and 17 and samples 15 and 18 shown in massless foundation in the second boundary condition imposed fewer tensions to the system. Comparison of the first and second boundary condition in DBE earthquake for models 1 and 19 and also 2 and 20 shown that the tensions and displacement in the horizontal earthquake is far greater than the vertical component.

\section{ACKNOWLEDGMENTS}

The study presented in this paper has been supported by Islamic Azad University, Parand Branch. The author would like to gratefully acknowledge this support.

\section{REFERENCES}

Zhou Yihong, Zhao Chunju. 2005. Intelligent model of uniongrid in construction simulation of RCC dam. Hydroelectric Energy, (5): 47-50 (in Chinese)

WU Zhong-ru, GU Chong-shi, WU Xiang-hao. 2001. RCCD safety monitoring theory and its application [M]. Beijing: Science Press,: 96-111. (in Chinese)

A.B.C. Larson Douglas, 2009. Reliably Safe American Scientist 96 (1) 6, http://dx.doi.org/10.1511/2008.69.6.

US Army Corps of Engineers,1997. Willow Creek Lake, June 18, Retrieved 2009.

Chuhan, Z. Guanglun, W. Shaomin, W. Yuexing, D. 2002. Experimental tests of rolled compacted concrete and nonlinear fracture analysis of rolled compacted concrete dams. Journal of Materials in Civil Engineering, vol. 14 (2), pp.108-115.

Zuohui, P., 2004. Material model of high roller compacted concrete dam. Journal of Dam Engineering, vol. 12, pp. 143166.

Esmaeilnia Omran, M and Mehdilu Torkamani, H., 2012. The safety and stability control of Jegin RCC dam using dynamic time history analysis. Ninth International Congress of Civil Engineering, Isfahan University of Technology 19-21.

GU Chong, s. and WEI Bo, w. and XU Zhen, K. and LIU Da, w., 2013. Fluid-solid coupling model based on end chronic damage for roller compacted concrete dam. J. Cent. South Univ. 20: $3247-3255$

Wolf, J.P., 1985. Dynamic soil-structure-interaction analysis. Prentice-Hall, Englewood Cliffs, NJ.

Ghaemian, M. ,2000. Concrete dams: Seismic analysis, Design and Retrifitting.

Zhang, S., Wang, G., and Yu, X., 2013. Seismic cracking analysis of concrete gravity dams with initial cracks using the extended finite element method. Engineering Structures, Vol. 56, pp. 528-543.

Abaqus Inc., 2010. Abaqus theory manual, Version 6.1. Abaqus Inc.(n.d.).

Khaled Ghaedi, Mohammed Jameel, Zainah Ibrahim, and Khanzaei, P., 2015. Seismic analysis of roller compacted concrete (RCC) dams considering effect of sizes and shapes of galleries. KSCE Journal of Civil Engineering, pp. 1-12. 
Noorzaeia J., Bayagooba K.H., Thanoonb W.A., Jaafara M.S., 2006. Thermal and stress analysis of Kinta RCC dam, Engineering Structures Vol. 28, pp. $1795-1802$.

Board of Engineers Malaysia (BEM), 2006. Engineering Practice

Burman A., Maity D., Sreedeep, S., 2010. Iterative analysis of concrete gravity dam-nonlinear foundation interaction, International Journal of Engineering, Science and Technology Vol. 2, No. 4, pp. 85-99.

Heirany Z., Ghaemian M, 2012. Effect of Foundation in Dynamic Analysis of Concrete Gravity Dams", GRAĐEVINAR, 64 (8, 641-646.

Heirany Z., Ghaemian M., 2012. The Effect of Foundation's Modulus of Elasticity on Concrete Gravity Dam's Behavior, Indian Journal of Science and Technology, Vol. 5 No. 5 .

Lysmer, J., Kuhlemeyer, R.L., 1969. Finite Dynamic Model for InfiniteMedia, Journal of Engineering Mechanics Division, ASCE, 95, pp. 859-877.

Miura, F., Okinaka, H., 1989, Dynamic Analysis Method for 3D Soil-Structure Interaction Systems with the Viscous Boundary Based on the Principle of Virtual Work, Japanese Journal of Civil Engineering, pp. 395-404. 